\title{
THE EFFICIENCY OF VENTILATION DURING VOLUNTARY HYPERPNEA: STUDIES IN NORMAL SUBJECTS AND IN DYSPNEIC PATIENTS WITH EITHER CHRONIC PUL- MONARY EMPHYSEMA OR OBESITY *
}

\author{
By H. W. FRITTS, JR., J. FILLER, A. P. FISHMAN and A. COURNAND
}

\author{
(From the Department of Medicine, Columbia University, College of Physicians and Surgeons, \\ and the Cardio-Pulmonary Laboratory of the First Medical and Chest Services, \\ Columbia University Division, Bellevue Hospital, New York, N. Y.)
}

(Submitted for publication February 24, 1959; accepted April 9, 1959)

The ventilatory apparatus is analogous to a mechanical system composed of an engine coupled to a pump. The engine comprises the chest wall and the diaphragm, while the pump embraces the airways and the lungs. Although the two units operate as a single assembly, their functions are distinct. The engine converts metabolic energy into mechanical work; the pump translates this work into a rhythmic exchange of air.

According to this schema, the useful work of the chest wall and diaphragm is that performed on the surfaces of the lungs. Hence, the efficiency with which this work is accomplished is defined by the formula written below.

Per cent efficiency

$$
=\frac{\begin{array}{c}
\text { mechanical work performed } \\
\text { on the lungs }
\end{array}}{\text { total energy used for breathing }} \times 100 \text {. }
$$

Using this formula, we have calculated the efficiencies of seven normal subjects, of six patients with chronic pulmonary emphysema, and of five patients who were obese. A presentation of these data is the purpose of this report.

\section{METHODS}

a) Estimation of the energy used for breathing. The energy used for breathing was estimated by using a modification (1) of the method of Liljestrand (2). In brief, the procedure entailed measuring the oxygen uptake first at rest, then at from 10 to 20 different levels of voluntary hyperpnea. At each level the subject breathed a gas mixture containing a small concentration of carbon dioxide; this prevented the development of hypocapnia and enabled the subject to maintain an augmented volume of ventilation for 20 minutes, a sufficiently long period for the establishment of a steady state. During the

* This investigation was supported by a research grant (Public Health Service) (Grant H-2001 C) from the National Heart Institute, National Institutes of Health. final two minutes of each period the ventilation was measured and collections of expired gas were made. Two samples of this gas were analyzed for oxygen and carbon dioxide; duplicate analyses were required to check within 0.03 volume per cent.

In each of the experimental periods, the subject breathed at a frequency of 30 breaths per minute by following the rhythm set by a metronome. This frequency was chosen because the subject could achieve a large minute volume of ventilation with a small tidal volume of air. Although the size of the tidal volume did not affect the measurement of energy, it appeared to be an important factor in the measurement of work. The reasons for this importance are outlined in Part $b$ of this section; they indicated that measurements of work were most reliable when the tidal volumes were small.

The data from those experiments in which the respiratory quotients lay outside the range of 0.70 to 0.95 were discarded. The data from the remaining runs were plotted on coordinate axes, and the curve that provided the best visual fit was drawn through the points (Figure $1, \mathrm{~A})$. Since such a curve did not directly indicate the total oxygen used for breathing, this quantity was estimated by following these steps: 1) The oxygen used for quiet breathing at a frequency of 30 was calculated by multiplying the slope of the lowermost end of the curve by the resting ventilation. 2) This product was subtracted from the resting oxygen uptake to define a baseline value. Then 3 ) the total oxygen used for breathing at any level of ventilation was estimated by subtracting this value from the oxygen uptake measured during hyperpnea. In effect, this resolved the total oxygen uptake into two components : a nonrespiratory component which was assumed to stay constant, and a respiratory component which became larger as the ventilation increased.

The oxygen used for breathing was converted to equivalent kilogram-meters ( $\mathrm{Kg}$. M.) of energy by multiplying the respiratory component, expressed as cc. $\mathrm{O}_{2}$ per minute, by the factor 2.06 (3). Implicit in the use of this factor were the premises that the oxygen was utilized solely for the combustion of fat and carbohydrate, and that these foodstuffs were consumed in such proportions that the respiratory quotient had an average value of 0.8 .

b) Estimation of the mechanical work performed on the lungs. The mechanical work performed on the lungs 
was estimated from the areas of pressure-volume diagrams. For the construction of these diagrams it was necessary to know the change in the volume of the lungs and the difference in pressure between the mouth and the pleural space. Changes in volume were measured by graphic integration of the signal of a Mead-Silverman pneumotachygraph. A preliminary study of this instrument indicated that its response was linear for flow rates between 0 and $190 \mathrm{~L}$. per minute, and that its calibration was not perceptibly altered when the fraction of oxygen in the calibrating mixture was varied between 16 and 25 per cent, and the fraction of carbon dioxide between 0 and 8 per cent. But despite this insensitivity to changes in gas composition, other factors-notably temperature, water vapor and the respiratory quotient-caused the inspired and expired volumes to differ by sufficient amounts to preclude the construction of closed-loop pressure volume diagrams. The effects of these factors, previously analyzed by Mead and Whittenberger (4), were such that when dry gas was inspired at a temperature of $24^{\circ} \mathrm{C}$. and under a pressure of one atmosphere, the change in the volume of the lungs was about 10 per cent greater than the volume of air entering the mouth. During expiration the temperature of the gas leaving the mouth was about $32^{\circ} \mathrm{C}$. (4), and the volume measured by the pneumotachygraph was about 3 per cent smaller than the actual change in the size of the lungs. Thus, the expired volume usually exceeded that inspired by approximately 7 per cent.

To minimize the disparity between these volumes, we converted each to a B.T.P.S. value by using the measured temperature of the inspired gas mixture and by using $32^{\circ}$ C. as the approximate temperature of the expired gas. In most instances these conversions minimized the difference between the volumes to the extent that the small remaining discrepancy could be ignored.

The other variable needed to construct pressure-vol- ume diagrams was the pressure-difference between the mouth and the pleural space. For this value we substituted the pressure-difference between the mouth and the lumen of the esophagus. To test the validity of this substitution, we followed the procedure of others (5-9) and compared the two pressure-differences in nine patients with pneumothorax. The intraesophageal pressure was recorded through a No. 7 water-filled cardiac catheter which, after being softened by heating in warm water, was advanced through the nose until the tip lay at the level of the pulmonary artery. The pressure in the esophagus referred to atmosphere was measured by connecting the catheter to a Statham gage, the level of the gage having previously been adjusted to the height of the angle of Louis. Because the catheter was filled with water, a correction had to be made for the difference in heights of the tip of the catheter and the tip of the gage. To make this correction, a lateral X-ray of the chest was taken with a plate of three-fourths inch lucite interposed between the body of the subject and the X-ray cassette. The lucite plate contained a grid of radiopaque brads, and the images of the brads were superimposed on the X-ray film of the lateral view of the chest. Since these brads were spaced at one centimeter distances, the difference in heights of the gage and the angle of Louis could be determined by drawing horizontal lines through the levels and counting the brad spaces between the two. This distance, measured in centimeters, was added to the gage pressure to give the pressure in the esophagus referred to atmosphere.

For the measurement of intrapleural pressure, a No. 14 trocar was inserted through the chest wall and a polyethylene tube of $2 \mathrm{~mm}$. internal diameter was threaded through the lumen. After removing the trocar, we recorded the intrapleural pressure by attaching the polyethylene tube to a second Statham gage. The system used to record this pressure had characteristics similar
(A)

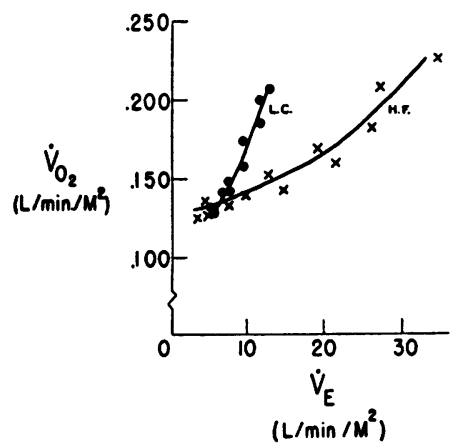

(B)

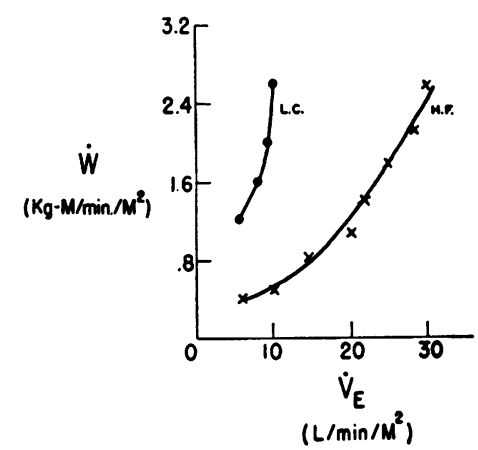

Fig. 1. Relation Between Oxygen Uptake ( $\left.\nabla_{O_{2}}\right)$ and Ventilation $\left(\dot{V}_{\text {f }}\right)$ in H.F., a Normal Subject, and in L.C., a Patient with Chronic Pulmonary Emphysema (A); and Relation Between Mechanical Work Performed on the Lungs ( $\dot{W}$ ) and Ventilation ( $V_{E}$ ) in the Same Two Subjects (B) 
(A)

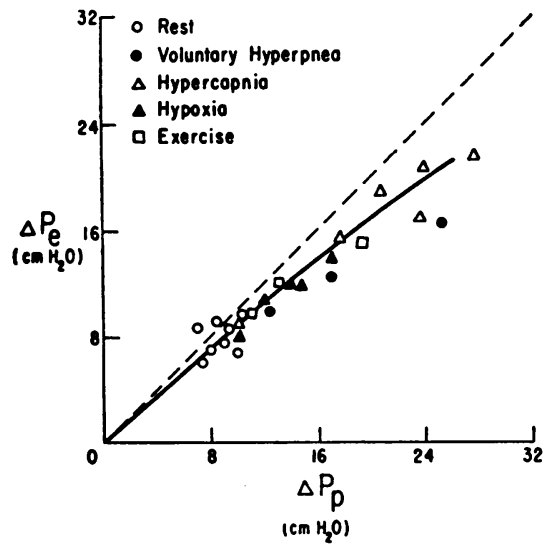

(B)

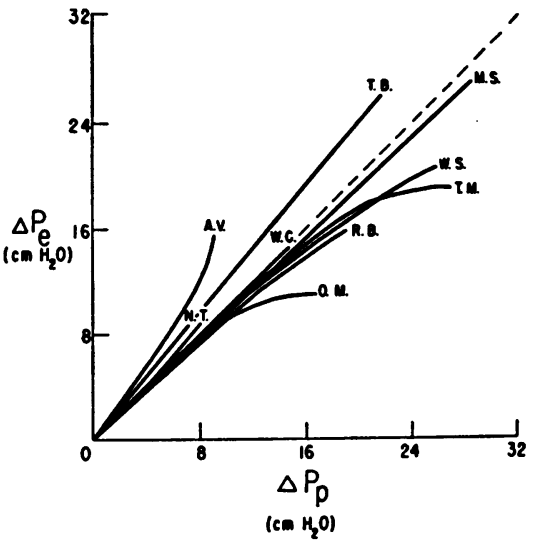

Fig. 2. Comparison of Swings in Intraesophageal Pressure $\left(\triangle P_{e}\right)$ with Swings in Intrapleural Pressure $\left(\triangle P_{P}\right)$ in Subject W.S. DURing Quiet and Augmented Ventilation (A) and Comparison of $\triangle P_{e}$ And $\triangle P_{P}$ in all Nine PaTIENTS With PNeUmothorax (B)

to those of the system used to measure the pressure in the esophagus. The natural frequency of the former was 39 cycles per second (cps), and of the latter, $28 \mathrm{cps}$.

All measurements were made with the subject supine. Diverse stimuli were employed to increase the ventilation, including exercise, the inhalation of 5 per cent $\mathrm{CO}_{2}$, and the inhalation of 12 per cent $\mathrm{O}_{2}$. In addition, each patient changed his minute volume of ventilation by voluntarily altering his rate and depth. With each stimulus or voluntary alteration, the pressures in the two spaces were compared in two ways: 1 ) the magnitude of the swings in pressure (i.e., the difference between peak inspiratory and peak expiratory pressures) averaged over at least 10 respiratory cycles, and 2) the mean pressures obtained by planimetric integration of the pressure records.

Nine patients, each with either a spontaneous or an induced pneumothorax, were studied. The agreement of the swings in pressure are presented in Figure 2. The construction of the curve of agreement in Patient W.S. is shown in Figure 2, A, and the curves of all nine patients are shown in Figure 2, B. These curves indicated that the agreement was independent of the stimulus used to increase ventilation, and that the correlation was best at low tidal volumes when the swings in pressure were small. Because the correlation became less and less satisfactory as the tidal volume became larger, all studies of efficiency were carried out at a frequency of 30 breaths per minute. As previously mentioned, this frequency allowed the achievement of a large minute volume of ventilation with a small tidal volume of air.

In general, the correspondence between the mean pressures in the two spaces was poor. At rest the mean intraplueral pressure referred to the mouth varied between -1 and $-5 \mathrm{~cm} . \mathrm{H}_{2} \mathrm{O}$, while that in the esophagus varied between +5 and $-3 \mathrm{~cm} . \mathrm{H}_{2} \mathrm{O}$. Moreover, the relationship between the mean pressures in any single patient was frequently inconstant and was almost always altered, sometimes to a considerable degree, when the minute volume of ventilation was changed. For example, in the patient whose data are plotted in Figure 2, A, the mean pressure in the esophagus referred to the mean pressure in the pleura varied between -1 and +5 $\mathrm{cm}$. $\mathrm{H}_{2} \mathrm{O}$ when different stimuli were applied. These results support those published previously by Cherniack, Farhi, Armstrong and Proctor (9).

Because the correlation between the mean pressures was not satisfactory, pressure-volume diagrams were con-

TABLE I

Physical characteristics of the subjects in Groups I, II and III

\begin{tabular}{llll}
\hline Subject & Age & BSA & Wt. \\
\hline & yrs. & $M_{\text {. }}^{2}$ & Kg.
\end{tabular}
Group I-Normal subjects

$\begin{array}{llll}\text { G.P. } & 32 & 1.91 & 75.1 \\ \text { H.F. } & 35 & 1.94 & 77.2 \\ \text { R.B. } & 30 & 2.10 & 91.3 \\ \text { J.F. } & 41 & 1.86 & 72.6 \\ \text { C.B. } & 19 & 1.62 & 53.6 \\ \text { A.S. } & 47 & 1.89 & 67.0 \\ \text { A.D. } & 56 & 2.04 & 84.8\end{array}$

Group II-Patients with chronic pulmonary emphysema

$\begin{array}{llll}\text { T.B. } & 61 & 1.84 & 68.5\end{array}$

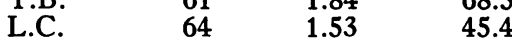

W.L. $\quad 54 \quad 1.80 \quad 55.3$

$\begin{array}{llll}\text { E.E. } & 66 & 1.78 & 64.6\end{array}$

$\begin{array}{llll}\text { D.G. } & 53 & 1.76 & 90.6\end{array}$

$\begin{array}{llll}\text { J.G. } & 49 & 1.77 & 70.6\end{array}$

Group III-Obese patients

$\begin{array}{llll}\text { H.W. } & 36 & 2.13 & 137.0 \\ \text { G.W. } & 55 & 2.30 & 127.0 \\ \text { J.B. } & 40 & 2.34 & 120.0 \\ \text { M.S. } & 33 & 2.46 & 136.6 \\ \text { A.H. } & 61 & 2.48 & 141.0\end{array}$


TABLE II

Results of pulmonary function tests and arterial blood analyses in the patients in Groups II and III

\begin{tabular}{|c|c|c|c|c|c|c|c|c|c|}
\hline Subject & MBC* & $\mathrm{VC} \dagger$ & TLC $\ddagger$ & $\frac{\mathrm{RV}}{\mathrm{TLC}} \delta \times 100$ & $\begin{array}{l}\text { Alveolar } \mathrm{N}_{2} \\
\text { after } 7 \mathrm{~min} \text {. } \\
\text { oxygen }\end{array}$ & $\mathrm{Ht} \|$ & $\mathrm{S}_{\mathrm{aO}_{2}}$ 的 & $\mathrm{pH}_{\mathrm{s}}{ }^{* *}$ & $\mathrm{Pacoz}{ }^{\dagger} \dagger$ \\
\hline & $\%$ predicted & $\begin{array}{r}\% \text { predicted } \\
\text { Group }\end{array}$ & $\begin{array}{l}\% \text { predicted } \\
\text {-Patients }\end{array}$ & $\begin{array}{c}\% \\
\text { h chronic }\end{array}$ & $\begin{array}{c}\text { vol. } \% \\
\text { nonary emp }\end{array}$ & $\begin{array}{c}\% \\
\text { sema }\end{array}$ & $\%$ & & $\mathrm{~mm} . \mathrm{Hg}$ \\
\hline $\begin{array}{l}\text { T.B. } \\
\text { L.C. } \\
\text { W.L. } \\
\text { E.E. } \\
\text { D.G. } \\
\text { J.G. }\end{array}$ & $\begin{array}{l}38 \\
31 \\
46 \\
37 \\
49 \\
63\end{array}$ & $\begin{array}{l}61 \\
44 \\
81 \\
89 \\
80 \\
83\end{array}$ & $\begin{array}{r}91 \\
112 \\
115 \\
115 \\
100 \\
110\end{array}$ & $\begin{array}{l}53 \\
71 \\
52 \\
46 \\
44 \\
41\end{array}$ & $\begin{array}{l}3.10 \\
5.40 \\
3.87 \\
\\
8.20 \\
8.40\end{array}$ & $\begin{array}{l}48 \\
39 \\
54 \\
48 \\
50\end{array}$ & $\begin{array}{l}96 \\
85 \\
90 \\
94 \\
90 \\
84\end{array}$ & $\begin{array}{l}7.41 \\
7.35 \\
7.33 \\
7.49 \\
7.51\end{array}$ & $\begin{array}{l}35 \\
49 \\
46 \\
34 \\
30\end{array}$ \\
\hline \multicolumn{10}{|c|}{ Group III-Obese patients } \\
\hline $\begin{array}{l}\text { H.W. } \\
\text { G.W. } \\
\text { J.B. } \\
\text { M.S. } \\
\text { A.H. }\end{array}$ & $\begin{array}{l}75 \\
57 \\
70 \\
64 \\
50\end{array}$ & $\begin{array}{r}88 \\
105 \\
82 \\
93 \\
75\end{array}$ & $\begin{array}{r}102 \\
112 \\
107 \\
95 \\
112\end{array}$ & $\begin{array}{l}30 \\
33 \\
38 \\
22 \\
52\end{array}$ & $\begin{array}{l}1.32 \\
1.36 \\
2.39 \\
1.74 \\
3.79\end{array}$ & $\begin{array}{l}50 \\
57 \\
39 \\
49 \\
46\end{array}$ & $\begin{array}{l}85 \\
97 \\
90 \\
93 \\
89\end{array}$ & $\begin{array}{l}7.39 \\
7.33 \\
7.39 \\
7.41 \\
7.44\end{array}$ & $\begin{array}{l}45 \\
40 \\
47 \\
31 \\
37\end{array}$ \\
\hline
\end{tabular}

* $\mathrm{MBC}=$ maximum breathing capacity.

$+\mathrm{VC}=$ vital capacity.

$\ddagger$ TLC $=$ total lung capacity.

$\S \mathrm{RV}=$ residual volume.

structed in the conventional manner on the assumptions that: 1) The pressure difference across the lungs at the start of inspiration was zero, and 2) the muscles of the chest and abdominal walls contributed to the work of expiration only when the intraesophageal pressure during expiration exceeded that at the start of inspiration. The errors introduced by these assumptions are considered in the Discussion.

The values of work calculated for the different levels of hyperpnea were used to construct curves relating work to ventilation. Typical curves are shown in Figure 1, B.

c) The calculation of efficiency. Efficiency was calculated by dividing the mechanical work performed on the lungs per minute by the corresponding energy consumption. Multiplication of this value by 100 allowed the values of efficiency to be expressed as percentages.

\section{SUBJECTS}

The ages, body surface areas and body weights of the subjects are presented in Table I. With a single exception (C.B.), all of the subjects were men.

Group I-Normal subjects. Four members of the laboratory staff and three patients with minimal apical tuberculosis served as controls. The three patients were asymptomatic and had been ambulatory for several months prior to the time when the tests were performed.

Group II-Patients with chronic pulmonary emphysema. This group was composed of six patients who exhibited the clinical, roentgenologic and physiologic signs of moderate or advanced chronic pulmonary emphysema, but who had no evidence of cysts. The results of the pulmonary function tests, presented in Table II, indicated that each of the patients had a smaller than normal maximum breathing capacity and a larger than normal ratio of residual volume to total lung capacity. Four pa-
$\mathrm{Ht}=$ hematocrit.

I $\mathrm{S}_{\mathrm{aO}_{2}}=$ arterial blood oxyhemoglobin saturation.

$\mathrm{pH}_{\mathrm{s}}=$ serum $\mathrm{pH}$.

$\dagger \mathrm{P}_{\mathrm{aCO}_{2}}=$ arterial blood carbon dioxide tension.

tients had arterial blood oxygen unsaturation at rest, and two of these four had elevated blood tensions of carbon dioxide.

Group III-Obese patients. Five obese patients who complained of dyspnea on exertion were included in this group. The results of the pulmonary function tests and the arterial blood studies are shown in Table II. Patient A.H. presumably suffered from arteriosclerotic heart disease and had been in congestive heart failure one year previously. At the time of the study he had been maintained satisfactorily for nine months on a regimen which included a low salt diet, weekly injections of Mercuhydrin (meralluride) and a daily dose of digitalis.

\section{RESULTS}

The results are presented in Tables III, IV and $\mathrm{V}$. The tabulated numbers were obtained from curves such as those drawn in Figure 1.

\section{a) Energy used for breathing}

The total energy used for resting ventilation by the normal subjects varied between 0.8 and 1.9 $\mathrm{Kg}$. M. per L. per minute, while that used by the patients with emphysema varied between 2.1 and 8.5 Kg. M. per L. per minute. These observations agree with those previously made in this laboratory (1). The values recorded in the obese patients were larger: They ranged between 6.6 and $26.2 \mathrm{Kg}$. M. per L. per minute.

The energy used for ventilation during voluntary hyperpnea showed considerable individual 
TABLE III

Values of ventilation, energy, work and efficiency recorded in the seven normal subjects in Group I

\begin{tabular}{|c|c|c|c|c|}
\hline Subject & Ventilation & $\begin{array}{l}\text { Energy cost } \\
\text { of breathing }\end{array}$ & $\begin{array}{c}\text { Mechanical } \\
\text { work performed } \\
\text { on lungs }\end{array}$ & Efficiency \\
\hline G.P. & $\begin{array}{c}L . / \min . / M .2 \\
5 \\
10 \\
15 \\
20\end{array}$ & $\begin{array}{c}\text { Kg.M./min. } / M .2 \\
5 \\
21 \\
44 \\
75\end{array}$ & $\begin{array}{c}\text { Kg.M./min. } / M .^{2} \\
0.1 \\
0.3 \\
0.6 \\
1.0\end{array}$ & $\begin{array}{l}\% \\
2 \\
1.4 \\
1.4 \\
1.3\end{array}$ \\
\hline H.F. & $\begin{array}{r}7 \\
10 \\
15 \\
20 \\
25 \\
30\end{array}$ & $\begin{array}{r}6 \\
9 \\
19 \\
36 \\
61 \\
95\end{array}$ & $\begin{array}{l}0.4 \\
0.5 \\
0.8 \\
1.1 \\
1.8 \\
2.5\end{array}$ & $\begin{array}{l}6.7 \\
5.6 \\
4.2 \\
3.1 \\
3.0 \\
2.6\end{array}$ \\
\hline R.B. & $\begin{array}{r}5 \\
10 \\
15 \\
20 \\
25 \\
30 \\
35\end{array}$ & $\begin{array}{r}6 \\
14 \\
26 \\
51 \\
90 \\
137 \\
189\end{array}$ & $\begin{array}{l}0.2 \\
0.4 \\
0.7 \\
1.0 \\
1.6 \\
2.7 \\
2.4\end{array}$ & $\begin{array}{l}3.3 \\
2.9 \\
2.7 \\
2.0 \\
1.8 \\
2.0 \\
2.2\end{array}$ \\
\hline J.F. & $\begin{array}{r}5 \\
10 \\
15 \\
20 \\
25\end{array}$ & $\begin{array}{r}9 \\
23 \\
36 \\
74 \\
99\end{array}$ & $\begin{array}{l}0.2 \\
0.4 \\
0.6 \\
0.9 \\
1.3\end{array}$ & $\begin{array}{l}2.2 \\
1.7 \\
1.7 \\
1.2 \\
1.3\end{array}$ \\
\hline C.B. & $\begin{array}{l}10 \\
12 \\
14 \\
16 \\
18 \\
20\end{array}$ & $\begin{array}{r}9 \\
11 \\
17 \\
24 \\
33 \\
48\end{array}$ & $\begin{array}{l}0.5 \\
0.7 \\
0.8 \\
1.0 \\
1.2 \\
1.5\end{array}$ & $\begin{array}{l}5.6 \\
6.4 \\
4.7 \\
4.2 \\
3.6 \\
3.1\end{array}$ \\
\hline A.S. & $\begin{array}{r}3 \\
5 \\
7 \\
9 \\
11 \\
13 \\
15 \\
17\end{array}$ & $\begin{array}{r}6 \\
10 \\
23 \\
31 \\
45 \\
60 \\
78 \\
97\end{array}$ & $\begin{array}{l}0.2 \\
0.3 \\
0.4 \\
0.5 \\
0.6 \\
0.8 \\
0.9 \\
1.2\end{array}$ & $\begin{array}{l}3.3 \\
3.0 \\
1.7 \\
1.6 \\
1.3 \\
1.3 \\
1.2 \\
1.2\end{array}$ \\
\hline A.D. & $\begin{array}{l}10 \\
15 \\
20 \\
25 \\
30 \\
35\end{array}$ & $\begin{array}{r}18 \\
27 \\
50 \\
100 \\
176 \\
250\end{array}$ & $\begin{array}{l}0.6 \\
1.0 \\
1.7 \\
2.5 \\
3.5 \\
4.6\end{array}$ & $\begin{array}{l}3.3 \\
3.7 \\
3.4 \\
2.5 \\
2.0 \\
1.8\end{array}$ \\
\hline
\end{tabular}

variation. In general, the energy expenditure at a particular level of ventilation was larger in the patients with emphysema and in the obese patients than it was in the subjects in the control group.

\section{b) Mechanical work performed on the lungs}

The values of work measured in the normal subjects were slightly larger than those reported by others. This is probably attributable to the imposed frequency of 30 , rather than the lower, spontaneous frequencies which the subjects might naturally have chosen.

In accord with previous observations, the work required for any particular minute volume was larger in the patients with emphysema than in the normal subjects. Although the values were possibly different at the frequency of 30 than they would have been for the same minute volume respired at a lower frequency, the calculated amounts of work correspond to those previously reported for patients with disease of comparable severity.

The work performed on the lungs was abnormally high in only two of the obese patients. In the remaining three, the values were of the same order of magnitude as those recorded for the subjects in the control group.

\section{c) Efficiency}

The values of efficiency calculated for the normal subjects are plotted in Figure 3. In general, the efficiencies were maximal during resting venti-

TABLE IV

Values of ventilation, energy, work and efficiency recorded in the six patients with chronic pulmonary emphysema in Group II

\begin{tabular}{|c|c|c|c|c|}
\hline Subject & Ventilation & $\begin{array}{l}\text { Energy cost } \\
\text { of breathing }\end{array}$ & $\begin{array}{l}\text { Mechanical } \\
\text { work performed } \\
\text { on lungs }\end{array}$ & Efficiency \\
\hline & $L . / \min . / M .^{2}$ & Kg.M. $/ \min . / M .{ }^{2}$ & $K g . M . / \min . / M .2$ & $\%$ \\
\hline T.B. & $\begin{array}{r}8 \\
12 \\
16 \\
18 \\
22\end{array}$ & $\begin{array}{r}48 \\
74 \\
118 \\
146 \\
211\end{array}$ & $\begin{array}{l}0.7 \\
0.9 \\
1.3 \\
1.5 \\
2.4\end{array}$ & $\begin{array}{l}1.5 \\
1.2 \\
1.1 \\
1.0 \\
1.1\end{array}$ \\
\hline L.C. & $\begin{array}{r}6 \\
8 \\
10\end{array}$ & $\begin{array}{r}56 \\
71 \\
109\end{array}$ & $\begin{array}{l}1.2 \\
1.6 \\
2.6\end{array}$ & $\begin{array}{l}2.1 \\
2.3 \\
2.4\end{array}$ \\
\hline W.L. & $\begin{array}{l}10 \\
12 \\
14\end{array}$ & $\begin{array}{r}48 \\
112 \\
162\end{array}$ & $\begin{array}{l}1.2 \\
1.8 \\
2.4\end{array}$ & $\begin{array}{l}2.5 \\
1.6 \\
1.5\end{array}$ \\
\hline E.E. & $\begin{array}{r}7 \\
9 \\
10 \\
13\end{array}$ & $\begin{array}{r}54 \\
70 \\
107 \\
146\end{array}$ & $\begin{array}{l}0.5 \\
0.8 \\
1.1 \\
1.6\end{array}$ & $\begin{array}{l}0.9 \\
1.1 \\
1.0 \\
1.1\end{array}$ \\
\hline D.G. & $\begin{array}{r}8 \\
14 \\
19 \\
25 \\
30\end{array}$ & $\begin{array}{r}19 \\
33 \\
52 \\
90 \\
120\end{array}$ & $\begin{array}{l}0.4 \\
0.9 \\
1.8 \\
2.8 \\
4.3\end{array}$ & $\begin{array}{l}2.1 \\
2.7 \\
3.1 \\
3.1 \\
3.6\end{array}$ \\
\hline J.G. & $\begin{array}{r}9 \\
12 \\
14\end{array}$ & $\begin{array}{r}44 \\
113 \\
141\end{array}$ & $\begin{array}{l}0.8 \\
1.2 \\
1.6\end{array}$ & $\begin{array}{l}1.8 \\
1.1 \\
1.1\end{array}$ \\
\hline
\end{tabular}


TABLE V

Values of ventilation, energy, work and efficiency recorded in the five obese patients in Group III

\begin{tabular}{|c|c|c|c|c|}
\hline Subject & Ventilation & $\begin{array}{l}\text { Energy cost } \\
\text { of breathing }\end{array}$ & $\begin{array}{c}\text { Mechanical } \\
\text { work performed } \\
\text { on lungs }\end{array}$ & Efficiency \\
\hline H.W. & $\begin{array}{c}L . / m i k . / M .^{2} \\
5 \\
7 \\
9 \\
11 \\
13 \\
15\end{array}$ & $\begin{array}{c}\text { Kg.M./min. } / M .^{2} \\
43 \\
60 \\
79 \\
103 \\
131 \\
159\end{array}$ & $\begin{array}{c}\text { Kg.M./min./M.2 } \\
0.3 \\
0.5 \\
0.7 \\
0.9 \\
1.2 \\
1.5\end{array}$ & $\begin{array}{l}\% \\
0.7 \\
0.8 \\
0.9 \\
0.9 \\
0.9 \\
0.9\end{array}$ \\
\hline G.W. & $\begin{array}{r}5 \\
8 \\
10 \\
12\end{array}$ & $\begin{array}{l}130 \\
210 \\
261 \\
320\end{array}$ & $\begin{array}{l}0.6 \\
1.0 \\
1.4 \\
2.3\end{array}$ & $\begin{array}{l}0.5 \\
0.5 \\
0.5 \\
0.7\end{array}$ \\
\hline J.B. & $\begin{array}{r}6 \\
8 \\
10 \\
12 \\
14\end{array}$ & $\begin{array}{r}87 \\
118 \\
155 \\
184 \\
202\end{array}$ & $\begin{array}{l}1.2 \\
1.5 \\
1.8 \\
2.1 \\
2.5\end{array}$ & $\begin{array}{l}1.4 \\
1.3 \\
1.2 \\
1.1 \\
1.2\end{array}$ \\
\hline M.S. & $\begin{array}{r}6 \\
10 \\
15 \\
20 \\
25\end{array}$ & $\begin{array}{r}39 \\
68 \\
126 \\
191 \\
269\end{array}$ & $\begin{array}{l}0.8 \\
1.1 \\
1.6 \\
2.8 \\
4.5\end{array}$ & $\begin{array}{l}2.1 \\
1.6 \\
1.3 \\
1.5 \\
1.7\end{array}$ \\
\hline A.H. & $\begin{array}{r}5 \\
7 \\
9 \\
11\end{array}$ & $\begin{array}{r}69 \\
95 \\
124 \\
150\end{array}$ & $\begin{array}{l}0.3 \\
0.6 \\
0.9 \\
1.3\end{array}$ & $\begin{array}{l}0.4 \\
0.6 \\
0.7 \\
0.9\end{array}$ \\
\hline
\end{tabular}

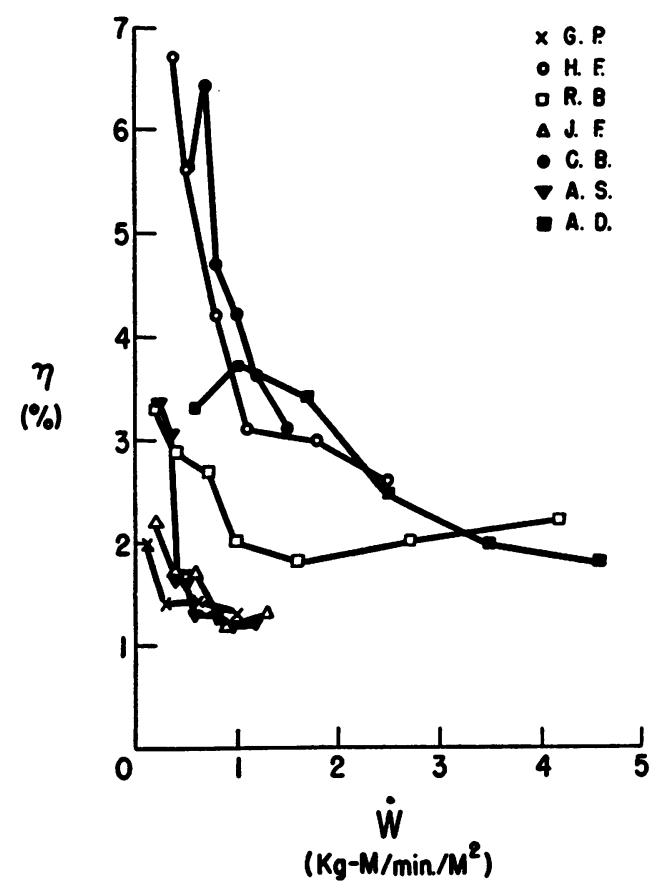

Fig. 3. Relation Between Efficiency $(\eta)$ and the Mechanical Work Performed on the Lungs ( $\dot{W}$ ) in the Seven Normal Subjects lation, then dropped progressively as the minute volume of ventilation was increased. The highest values were recorded in Subjects H.F. and C.B., each of whom realized an efficiency between 6 and 7 per cent.

The values of efficiency calculated for the patients with emphysema are compared to those of the normal subjects in Figure 4. Using the work performed per square meter of surface area as a reference, we found that three of the patients realized efficiencies comparable to those of the normal subjects, while the remaining three had efficiencies at the lower end of the normal range. These observations suggest that the chests of the patients with emphysema performed a given amount of work on the lungs with efficiencies not greatly different from normal. It is important to recognize, however, that this amount of work represents a large swing in pressure for a small change in volume. Hence, for any particular amount of work, the patients with emphysema derived a much smaller tidal exchange.

As can be see in Figure 5, the efficiencies of the

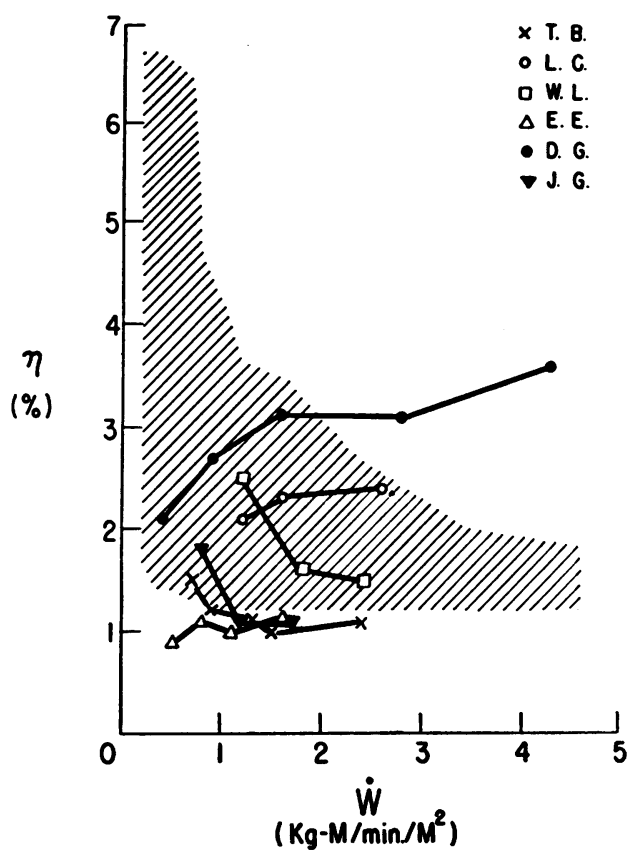

Fig. 4. Relation Between Effictency ( $\eta$ ) ANd the Mechanical Work Performed on the Lungs (W) in the Six Patients with Chronic Pulmonary EMPHYSEMA

The hatched area defines the locus of the curves of the normal subjects. 


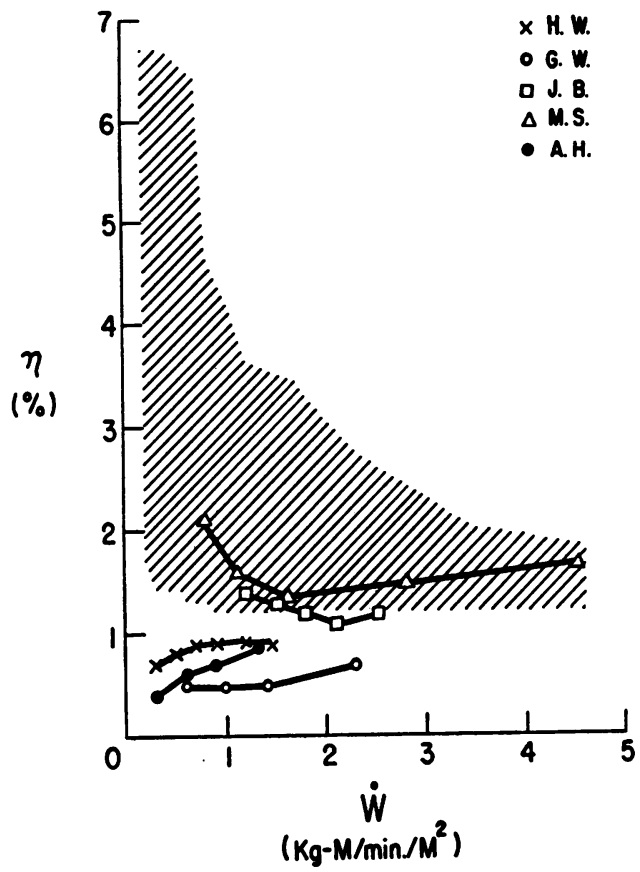

Fig. 5. Relation Between Efficiency ( $\eta$ ) and the Mechanical Work Performed on the Lungs (W) in the Five Obese Patients

The hatched area defines the locus of the curves of the normal subjects.

obese patients at all work loads tended to be lower than those found either in the normal subjects or in the patients with emphysema. Since the mechanical work performed on the lungs was either normal or only moderately increased, the reduction in efficiency was due to an abnormally high energy cost.

\section{DISCUSSION}

\section{A) Limitations of the methods used to estimate} energy and work

Liljestrand's method for estimating the oxygen cost of breathing (2) is based on the assumption that the extra oxygen used during augmented ventilation primarily reflects the extra oxygen utilized by the respiratory muscles in amplifying the excursions of the chest. This assumption seems reasonable, and the application of the principle has provided considerable information about the energetics of ventilation in both health and disease. However, the accuracy of the method is difficult to evaluate. For instance, the curves drawn in Figure 1, A represent visual averages of points that show considerable scatter, and near the resting level this scatter can markedly affect the estimates of both the change in the oxygen used for breathing and the total oxygen cost. During augmented ventilation, the scatter constitutes a smaller fraction of the respiratory component, and the oxygen used for breathing can be calculated with more confidence.

Comparable difficulties attend the calculation of the mechanical work performed on the lungs. This calculation is based on the concept that such work is done whenever the application of a pressure difference across a body produces a volume change. Hence,

$$
\mathrm{W}=\int \mathrm{PdV},
$$

where $\mathrm{W}=$ mechanical work, $\mathrm{P}=$ pressure difference, and $d V=$ incremental volume change.

When this relation is used to calculate the work performed on the lungs, two features must be recognized : 1) $\mathrm{P}$ is the difference in pressure existing between the mouth and the pleura; and 2) the use of a single value of $P$, such as that measured between the mouth and a point on the pleural surface, necessitates assuming that the pressure difference across the lungs is everywhere the same. Both of these features assume importance whenever the pressure in the esophagus is substituted for that in the pleura. Because the mean pressures in the two spaces are not well correlated $(9,10)$, pressure-volume diagrams must

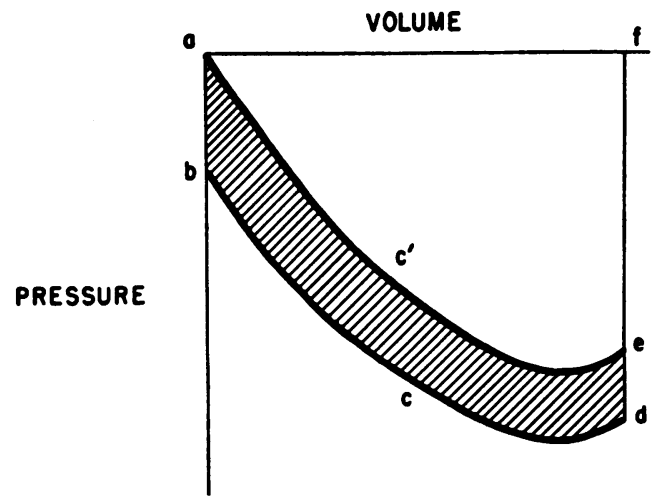

Fig. 6. Schematic Pressure-Volume Diagram Depicting the Theoretical Effect of Assuming that the Difference in Pressure Across the Lungs at THE Beginning of Inspiration is Zero

For explanation, see text. 


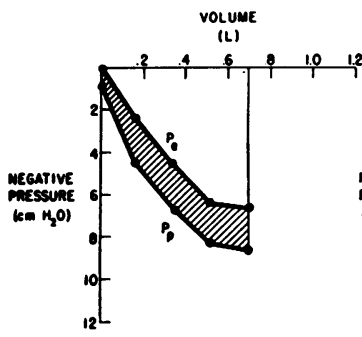

(A)

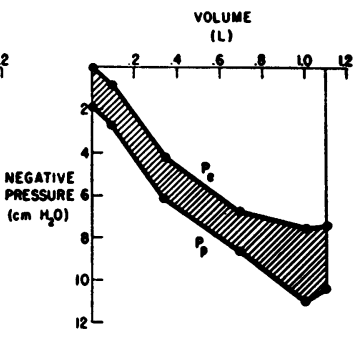

(B)
Fig. 7. Comparison of Pressure-Volume Diagrams Plotted Using Intraesophageal Pressure ( $P_{e}$ ) and Intrapleural Pressure ( $\left.P_{P}\right)$

In (A), the tidal volume was $0.7 \mathrm{~L}$., and in (B), $1.1 \mathrm{~L}$.

be plotted on the assumption that the pressure difference across the lungs at the start of inspiration is zero (10-14). The validity of this assumption is questionable, and its theoretical effect is illustrated in Figure 6 . In the drawing, the pressure-difference between the mouth and the pleura at the start of inspiration is indicated by the vertical distance $a b$, and the work of inspiration is represented by the area $a b c d e f a$. If, when using the esophageal pressure, $a b$ is assumed to be zero, then the work of inspiration is represented by the area $a c^{\prime} e f a$. In the latter instance, the work delineated by the hatched area is neglected, and the calculated work is less than that actually performed. To investigate the size of this error, we obtained simultaneous records of the change in the volume of the lungs, the intraesophageal pressure and the intrapleural pressure in one of the patients with pneumothorax. The diagrams of inspiratory work, plotted using each of the two pressures, are shown in Figures $7, \mathrm{~A}$ and $\mathrm{B}$. In $\mathrm{A}$, the tidal volume was $0.7 \mathrm{~L}$., and in $\mathrm{B}, 1.1 \mathrm{~L}$. At both levels the neglected work constituted about 35 per cent of the work calculated using the intrapleural pressure.

The discrepancy between the mean pressures in the esophagus and pleura also complicates the measurement of the work performed by the chest wall in deflating the lungs. Considerable evidence indicates that the work of a quiet expiration is accomplished by the elastic recoil of the pulmonary tissues, and in such an expiration the intrapleural pressure should remain less positive than the pressure of air at the mouth. By way of contrast, a forced expiration or an expiration against resistance can produce such positivity, indicating that work is being performed on the surfaces of the lungs. But since the mean pressure in the pleura is poorly correlated with that in the esophagus, the latter is an unreliable index of the point at which the reversal in sign takes place. In the present study, the element of active expiratory work was taken into account in the customary manner by using the positivity of the intraesophageal pressure above that at the start of inspiration as an indication that active work was being performed. Theoretically, this procedure can introduce an error into the calculation, and practically, the magnitude of this error cannot be directly assessed.

Finally, the use of esophageal pressure to calculate work also necessitates making the previously mentioned assumption that the drop in pressure across the lungs is everywhere the same. The validity of this assumption is questionable when applied in normal subjects, and it is especially suspect in patients with lung disease. If the pressure were different at different points on the lung surface, the calculation of work would necessitate first measuring the pressure and the volume change at each point on the pleura, and then substituting these values into Equation 2).

$W=\int P_{1} d V_{1}+\int P_{2} d_{2}+\cdots \int P_{n} d V_{n}$.

Such measurements are not feasible, and if they could be made, the calculation of work would be discouragingly complex.

For all of the aforementioned reasons, we believe that the use of esophageal pressure for estimating the work performed on the lungs may introduce errors of considerable magnitude, and we share the opinion of others that increments of work, rather than absolute values, may have the most validity.

\section{B) Efficiency with which the work on the lungs is accomplished}

The efficiency of the ventilatory apparatus has been considered in six previous publications. Rahn and his co-workers (15), Otis, Fenn and Rahn (16) and Otis alone (11) obtained values in normal subjects of 5 per cent or less. Cain and Otis (17) calculated the efficiency with which normal subjects performed work on external resist- 
ances and found values between 1 and 4 per cent. Subsequently, Campbell, Westlake and Cherniack (18) carried out similar experiments and obtained values between 8 and 10 per cent in a normal subject, and between 0.5 and 2 per cent in a patient with emphysema. More recently, Bartlett, Brubach, Trimble and Specht (19) have used similar methods in normal subjects and have obtained comparable results.

In the present study the chest wall and diaphragm have been depicted as an engine which performs mechanical work on the surfaces of the lungs. Work is also performed in displacing the chest wall, the diaphragm, and the organs of the mediastinum and abdomen which move with respiration, but this is considered to be a source of necessary but undesirable energy loss. Thus, the present use of the term "efficiency" does not afford specific insight into the efficiency of. the respiratory muscles. It does, however, afford a basis for the separation of patients with a high energy cost of breathing into two groups: 1) those in whom the increased cost is attributable to the lungs, and 2) others in whom it is not.

According to this concept, our data suggest that although a patient with emphysema is forced to perform abnormally large amounts of work to mobilize his lungs, this work is performed with an efficiency that is not greatly different from that realized by a normal person at a comparable work load. However, the two types of subjects have the important difference mentioned previously: For a particular amount of work performed on the lungs, the patient with emphysema derives a much smaller exchange of air.

The values of efficiency calculated for the obese patients tended to be low. Two of these patients (H.W. and J.B.) suffered from the effects of alveolar hypoventilation as indicated by high tensions of carbon dioxide in the arterial blood. Both patients expended inordinately large amounts of energy for breathing, despite the fact that the work performed on their lungs was not increased. These data can be explained by invoking either of two mechanisms: 1) The excess energy was used to impart motion to extrapulmonary structures; or 2) the muscles of the obese patients consumed excessive energy in performing a given amount of mechanical work. The first of these possibilities seems more likely because these pa- tients must have performed extra work in moving the adipose tissues overlying the chest and abdominal walls. The second possibility cannot be eliminated, although there is no evidence that the muscles of an obese person behave in an abnormal way.

Finally, it was emphasized previously that appreciable errors may attend the measurements of total energy and total work, and for this reason it is inappropriate to place too much emphasis on the calculated values of efficiency. However, changes in energy and work can be calculated with more assurance, and we compared the patients with emphysema and the obese patients in a second way. This second comparison entailed calculating the change in energy required to increase the work from 1.2 to $1.5 \mathrm{Kg}$. M. per minute per M. ${ }^{2}$. This particular increment in work was chosen because, with the exception of A.H., all of the patients in the two groups performed work in this range. The average value for the six patients with emphysema was $21 \mathrm{Kg}$. M. per minute per M. ${ }^{2}$, with a range of 5 to 31 . The average value for the four obese patients was $41 \mathrm{Kg}$. M. per minute per $\mathrm{M} .^{2}$, with a range of 21 to 57 . Hence, the data support the view that the obese patients expended excessive amounts of energy which could not be attributed to the work done on the lungs.

\section{SUM MARY}

The efficiency of the chest wall and diaphragm of seven normal subjects was less than 7 per cent. The efficiency of these structures in six patients with emphysema was not greatly different at any particular work load, although this work produced a smaller exchange of air.

By way of contrast, five obese patients had values of efficiency which tended to be low. Since these low values were attributable to inordinately high energy costs, the data are best explained by presuming that this extra energy was required to move the adipose tissues overlying the chest and abdominal walls. The possibility that the muscles were abnormal cannot be excluded, although there is no evidence to support this view. Whatever the reason for the extra energy consumption, its expenditure presumably contributed to the dyspnea these patients experienced on exercise. 


\section{REFERENCES}

1. Cournand, A., Richards, D. W., Jr., Bader, R. A., Bader, M. E., and Fishman, A. P. The oxygen cost of breathing. Trans. Ass. Amer. Phycns $1954,67,162$.

2. Liljestrand, G. Untersuchungen ueber die Atmungsarbeit. Skand. Arch. Physiol. 1918, 35, 199.

3. Hawk, P. B., Oser, B. L., and Summerson, W. H. Energy metabolism in Practical Physiological Chemistry, 12th ed. Philadelphia, The Blakiston Co., 1947, p. 659.

4. Mead, J., and Whittenberger, J. L. Physical properties of human lungs measured during spontaneous respiration. J. appl. Physiol. 1953, 5, 779.

5. Buytendijk, H. J. Intraesophageal Pressure and Lung Elasticity. Thesis, University of "Groningen, Holland, 1949.

6. Dornhorst, A. C., and Leathart, G. L. A method of assessing the mechanical properties of the lungs and air passages. Lancet 1952, 2, 109.

7. Fry, D. L., Stead, W. W., Ebert, R. V., Lubin, R. I., and Wells, H. S. The measurement of intraesophageal pressure and its relation to intrathoracic pressure. J. Lab. clin. Med. 1952, 40, 664 .

8. Mead, J., McIlroy, M. B., Selverstone, N. J., and Kriete, B. C. Measurement of intraesophageal pressure. J. appl. Physiol. 1955, 7, 491.

9. Cherniack, R. M., Farhi, L. E., Armstrong, B. W., and Proctor, D. F. A comparison of esophageal and intrapleural pressure in man. J. appl. Physiol. 1955, 8, 203.

10. Fritts, H. W., Jr., Fishman, A. P., Cournand, A., and Richards, D. W. Efficiency of ventilation dur- ing voluntary hyperpnea. Fed. Proc. 1955, 14, 51.

11. Otis, A. B. The work of breathing. Physiol. Rev. 1954, 34, 449.

12. Fritts, H. W., Jr., and Cournand, A. The effect of chronic obstructive emphysema on the efficiency of ventilation during voluntary hyperpnea. Abstracts Twentieth Internat. Cong. of Physiology, 1956, p. 315.

13. Otis, A. B. Estimation of work done on the lungs during breathing. Fed. Proc. 1957, 16, 97.

14. Fritts, H. W., Jr., and Richards, D. W. Respiratory system: External respiration in Medical Physics, 3rd ed. New York, Year Book Publishers. In press.

15. Rahn, H., Otis, A. B., Hodge, M., Epstein, M., Broutman, M., and Fenn, W. O. Com. on Aviation Med. Report No. 430, May 10, 1945.

16. Otis, A. B., Fenn, W. O., and Rahn, H. Mechanics of breathing in man. J. appl. Physiol. 1950, 2, 592.

17. Cain, C. C., and Otis, A. B. Some physiological effects resulting from added resistance to respiration in Studies in Respiratory Physiology, Air Force Technical Report No. 6528, August 1951, p. 190.

18. Campbell, E. J. M., Westlake, E. K., and Cherniack, R. M. Simple methods of estimating oxygen consumption and efficiency of the muscles of breathing. J. appl. Physiol. 1957, 11, 303.

19. Bartlett, R. G., Jr., Brubach, H. F., Trimble, R. C., and Specht, $H$. Relation of increased airway resistance to breathing work and breath velocity and acceleration patterns with maximum and near maximum breathing effort. J. appl. Physiol. 1958, 13, 194. 